\title{
FENOMENA PENURUNAN ANGKA PERNIKAHAN DAN PERKEMBANGAN BUDAYA OMIAI DI JEPANG
}

\author{
Budi Mulyadi \\ Fakultas Ilmu Budaya Universitas Diponegoro \\ Email: budi.mulyadi.live.undip.ac.id
}

\begin{abstract}
(Title: The Phenomenon Of Decline In Marriage Rates And Matchmaking Culture Development). The main goal of this article is to know the phenomenon of decline in marriage rates and matchmaking culture development in Japan.This reserach uses field research. Main methode are observation and interpretation.

This paper shows that one of the factor behind the marriage rtaes decline in Japan is the relatively new-found "freedom" that young Japanese have, as a result of decreasing social pressure to settle down and start a family. Japan has also seen a shift in attitudes among the sexes, with young women increasingly seen as career-orientated and putting their own desires ahead of the need for a family. Men, on the other hand, have become more willing to put up with unhappiness in their careers merely to hang on to their jobs as well as being less domineering toward women.

This paper also shows that there are development in Japanese mindset about matchmaking culture which take effect to decline in marriage rates in Japan.
\end{abstract}

Keywords: matchmaking; marriage; Japanese culture.

\section{PENDAHULUAN}

Jepang dikategorikan sebagai negara maju dengan perekonomian yang selalu meningkat tajam setiap tahunnya. Jepang bahkan pernah menduduki posisi kedua setelah Amerika sebagai negera yang paling kuat ekonominya di dunia. Hal tersebut disebabkan oleh budaya masyarakat Jepang yang memiliki karakter pekerja keras dan sangat mementingkan jenjang karir. Budaya kerja keras masyarakat Jepang menurunkan minat masyarakat Jepang untuk menikah dan memiliki keluarga di masa depan. Apalagi dengan pemikiran wanita modern saat ini di Jepang yang lebih mementingkan pendidikan dan karirnya daripada memiliki keluarga.

Menurut Jane Adams dalam Katrina Gulliver (2012:4), modernisasi yang terjadi di Jepang telah mengubah kondisi dan status wanita di Jepang. Dulu wanita Jepang tidak dibiarkan melakukan sesuatu atas kehendaknya sendiri, menjadi seorang istri dan melakukan pekerjaan rumah pada umumnya adalah hal yang lebih baik daripada menjadi seorang pembantu, buruh atau pekerja kasar lainnya. Namun, kini Jepang telah memberikan kebebasan untuk para wanita agar setara derajatnya dengan pria. Dan lagi, kini wanita di Jepang telah banyak membuat perubahan hingga banyak memunculkan tokoh penting wanita yang menginspirasi.

Wanita yang lebih memilih berkarir inilah yang menjadi salah satu faktor menurunnya angka kelahiran di Jepang, dikarenakan wanita lebih memilih bekerja daripada mengurus keluarga apalagi mempunyai anak. Dengan fenomena ini pemerintah Jepang pun sangat menekan warganya agar masalah penurunan tingkat 
Tersedia online di http://ejournal.undip.ac.id/index.php/kiryoku

kelahiran dapat ditanggulangi, namun banyak program dan strategi dari pemerintah yang masih belum mendapat hasil signifikan karena minimnya tanggapan positif dari masyarakat Jepang. Berbagai cara telah ditempuh oleh pemerintah Jepang dalam meningkatkan jumlah kelahiran dan minat untuk memiliki keturunan. Pemerintah

Jepang memulainya dengan mencanangkan "umeyō,fumeyō" yang bermakna "Mari Meningkatkan Kelahiran".

Semboyan tersebut diharapkan dapat mengajak masyarakat Jepang agar memiliki anak yang banyak dan dapat meningkatkan jumlah kelahiran. Selain itu pemerintah Jepang juga sudah menarik kembali kebijakan mengenai aborsi. Pemerintah Jepang menarik lagi aturan kebebasan aborsi dengan mengeluarkan larangan untuk melakukan tindakan aborsi kecuali untuk alasan kesehatan.

Selain itu pemerintah Jepang juga memberikan keringanan dengan memberikan cuti melahirkan dan setelah melahirkan bagi para ibu dan calon ibu. Cuti tersebut berlaku juga untuk para ayah agar mereka mendapatkan hak dan ikut berperan dalam menemani tumbuh kembang buah hatinya.

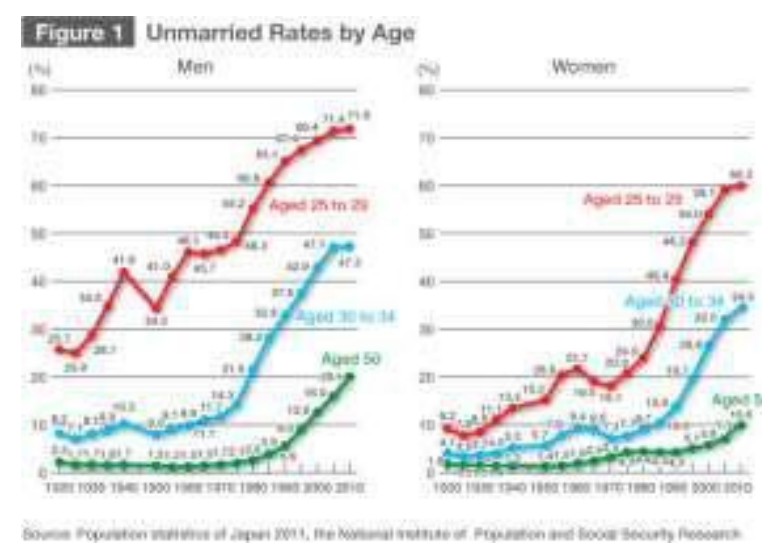

(http://www.nippon.com/en/i

n-depth/a01002/)

Pertama, penyebab utama penurunan jumlah anak di Jepang adalah banyaknya masyarakat Jepang yang belum menikah, seperti yang dilansirkan oleh
Yamada Masahiro. Kini di Jepang semakin banyak orang yang masih lajang, namun pasangan suami istri yang sudah memiliki anak, jumlahnya lebih sedikit dalam beberapa tahun terakhir. Dalam sensus nasional 2010, persentase yang belum menikah pada umur 30-34 tahun adalah 47,3\% (laki-laki) dan 34,5\% (perempuan) (gambar 1).

Melihat fakta dari data tersebut, maka jasa perjodohan sangatah berperan penting dalam meningkatkan angka kelahiran di Jepang. Perkembangan jasa perjodohan pun semakin bervariasi. Misalnya saja, pada zaman Showa dikenal istilah omiai atau biasa diartikan sebagai proses perjodohan dengan bantuan perantara atau nakodo. Sedangkan berkat perkembangan teknologi yang semakin pesat, di era globalisasi ini perjodohan yang dilakukan bisa menggunakan jaringan internet atau jika tak ingin repot, bisa menikah dengan orang yang sudah dikenal atau bahkan teman sendiri atau yang disebut dengan Kousai Zero Nichikon.

Berdasarkan penjelasan di atas tujuan dari penulisan artikel ini adalah untuk mengetahui faktor penyebab rendahnya angka pernikahan di Jepang; Untuk mengetahui perkembangan sistem perjodohan di Jepang dari zaman Showa hingga zaman Modern.

Adapun penelitian ini menggunakan penelitian kepustakaan (library research), dikarenakan bahan penelitian maupun data yang didapatkan adalah sumber-sumber pustaka dan internet. Sedangkan metode analisis data menggunakan metode kualitatif. Dimana menganalisis data berupa mencatat data dan mengklasifikasikannya.

\section{PEMBAHASAN}

\section{1) Faktor Penyebab Rendahnya Angka Pernikahan di Jepang}

Salah satu penyebab utama rendahnya angka pernikahan di Jepang adalah karena munculnya perubahan cara pandang wanita Jepang terhadap pernikahan. Dewasa ini 
banyak wanita yang Jepang yang lebih memilih berkarier daripada menikah. Banyak juga wanita Jepang yang menunda pernikahan. Linda Unsriana dalam penelitiannya yang berjudul " Perubahan Cara Pandang Wanita Jepang Terhadap Perkawinan dan Kaitannya dengan Shoushika" menjelaskan beberapa alasan wanita Jepang menunda pernikahan sebagai berikut. Dewasa ini banyak wanita Jepang yang senang hidup sendiri. Banyak wanita Jepang yang ingin menikmati hidup sendiri selama masih muda. Banyak wanita Jepang yang berpikir secara ekonomi susah memelihara rumah tangga setelah menikah. Mereka juga berfikir tidak merasakan daya tarik akan keuntungan dari menikah. Berubahnya kesadaran masyarakat mengenai usia menikah. Bertambahnya orang yang merasa lebih bersemangat bekerja daripada menikah. Kemungkinan besar kehilangan pekerjaan setelah menikah. Berkurangnya orang yang diminta tolong untuk pernikahan sehingga kurangnya kesempatan untuk bertemu. Lebih menyenangkan hidup dengan orang tua.

Faktor-faktor di ataslah yang menyebabkan semakin rendahnya angka pernikahan di Jepang.

\section{2) Perkembangan Budaya Perjodohan di Jepang}

Menurut Lebra (1984:102), Miai mempunyai dua definisi yaitu definisi secara sempit dan definisi secara luas. Definisi Miai secara sempit yaitu mempertemukan orang untuk tujuan tertentu. Sedangkan definisi luasnya yaitu perjodohan atau perkawinan yang terjadi atas bantuan perantara yang mempertemukan kedua belah pihak calon pengantin. Praktek perjodohan di Jepang sudah dilakukan pada tahun 60 an dikalangan para samurai. Para samurai menggunakan praktek perjodohan miai untuk mempertahankan garis keturunan aliansi yang kuat. Menurut Yoko Tokuhiro
(2009) konsep perjodohan semakin kuat dengan adanya Meiji Civil Code, dalam hal ini mendapatkan garis keturunan adalah tujuan utamanya. Sehingga pemilihan pasangan akan ditentukan oleh pihak keluarga dengan cara Miai. Namun setelah Perang Dunia Kedua, Meiji Civil Mode dihapuskan, para wanita dan pria lebih bebas untuk memilih pasangan dan peran keluarga untuk mencarikan pasangan pun semakin berkurang. Disinilah Miai mengalami penurunan.

Pasca Perang Dunia Kedua, Jepang mengalami Baby Boom, dimana tingkat kelahiran bayi disana sangat meningkat pesat. Adanya kebebasan dalam mencari pasangan Inilah yang menyebabkan maraknya terjadi hubungan seks bebas maupun pemerkosaan di Jepang hingga Baby Boom di Jepang tidak dapat dihindari lagi. Dengan adanya fenomena itulah, pemerintah Jepang melegalkan Undang Undang Aborsi. Dan semenjak di legalkannya aborsi di Jepang, tingkat kelahiran di Jepang langsung mengalami penurunan. Dengan rendahnya angka kelahiram di Jepang, sangat mempengaruhi jumlah populasi masyarakat Jepang. Dengan adanya kondisi tersebut, Jepang mulai mencanangkan kembali berbagai cara untuk meningkatkan populasi masyarakat Jepang. Salah satunya dengan tidak melegalkan lagi Undang - Undang Aborsi. Selain itu pemerintah Jepang juga sudah memberikan arahan pada warga Jepang untuk segera menikah dan meningkatkan angka kelahiran. Namun dengan kondisi masyarakat Jepang yang lebih memilih berkarir daripada berkeluarga dan mempunyai keturunan, menjadi suatu permasalahan yang sampai saat ini belum menemukan solusi tepatnya. Sehingga warga Jepang yang menyadari adanya dampak penurunan populasi penduduk, ikut berpikir untuk menemukan cara modern agar warga Jepang tertarik dengan pernikahan dan mempunyai keturunan yaitu dengan perjodohan. Dengan adanya hal itu muncullah kembali 
omiai yang dikemas dengan tatanan yang modern. Miai diadakan di sebuah restoran, bioskop atau pertunjukan musik di teater oleh nakoodo dan orang tua kedua calon pasangan. Kedua calon pasangan itu akan melanjutkan hubungan mereka atau tidak, tergantung pada perasaan mereka masingmasing setelah pertemuan itu dimana mereka saling menilai satu sama lain (Swann, 1983: 115-116)

Pada zaman Showa muncul "Kekkon Katsudo" yang merupakan adopsi dari omiai yang lebih modern. Pada tahun 2007, istilah Kekkon Katsudou ini mulai menjadi populer, sehingga membuat masyarakat Jepang sadar akan jodoh mereka tidak akan datang bila tidak dicari, hingga mereka akhirnya tidak sungkan untuk melakukan Kekkon Katsudou dengan mendatangi biro jodoh. Dengan adanya Kekkon Katsudou ini, tingkat angka pasangan yang menikah di Jepang semakin meningkat walaupun sedikit. Dapat dilihat pada grafik, pada tahun 2005 sempat terjadi peningkatan untuk angka pasangan yang menikah, tetapi tidak bertahan lama pada tahun 2010 hingga 2016 terjadi penurunan. Namun disela - sela penurunan angka pernikahan, pada tahun 2015 masyarakat Jepang dihebohkan dengan adanya fenomena Kousai Zero Nichikon. Dimana fenomena tersebut merupakan salah satu bentuk omiai yang lebih modern, namun dalam kasus ini, pasangan akan langsung menikah tanpa adanya proses berkencan dalam jangka waktu yang lama. Fenomena terbaru inilah yang semakin membuat masyarakat Jepang sadar untuk meningkatkan populasi penduduk. Seiring berkembangnya zaman, maka teknologi juga turut berkembang pesat. Salah satunya, teknologi informasi dan komunikasi, seperti internet. Hal tersebut mempengaruhi banyak aspek kehidupan. Tak terkecuali dalam menemukan jodoh. Jika pada zaman dahulu istilah perjodohan yakni "omiai". Seiring berkembangnya zaman, saat ini di negara Jepang, menemukan jodoh dengan memanfaatkan internet sudah tidak asing lagi di telinga masyarakatnya. Bahkan, ada sebuah lembaga yang disebut dengan Zenkoku Nakodo Rengokai yang berarti Asosiasi Perjodohan Nasional. Lembaga tersebut bisa dikatakan sebagai "upgraded version of omiai" karena beberapa sistem didalamnya masih menggunakan metode omiai yang digunakan pada zaman dahulu.Di dalam asosiasi tersebut, ada yang disebut sebagai penasihat. Orang yang bekerja sebagai penasihat, akan memberikan saran untuk kliennya tentang bagaimana sang klien harus bertindak jika ingin cepat mendapatkan jodoh. Selain melalui jasa Asosiasi Perjodohan Nasional, di Jepang ada pula situs online yang menawarkan jasa perjodohan. Misalnya saja, Tokyo-based M's Bridal. Situs tersebut diperuntukkan untuk orang yang mempunyai keseriusan untuk menikah namun belum menemukan pasangan klien diminta untuk mengisi formulir pendaftaran dan informasi berupa data diri, silsilah keluarga, riwayat kesehatan keluarga, dan bahkan data yang bersifat sangat personal. Namun, klien yang memilih untuk menggunakan situs ini, dikenakan harga yang cukup mahal, yakni 100,000 yen untuk biaya pendaftaran, dan 200.000 yen dibayarkan setelah pernikahan dilaksanakan. Selain itu, Tokyo-based M's Bridal juga diketahui sering menggelar pesta lajang yang tamunya dibatasi sesuai umur (hanya tamu wanita) dan pendapatan (hanya untuk laki-laki).

Karena banyaknya jasa perjodohan yang berperan sebgai perantara untuk menemukan jodoh, dapat dikatakan bahwa masyarakat Jepang sudah pasrah dan tak ingin repot dalam mencari jodoh. Sebuah survey yang dilakukan oleh The Cabinet Office Japan kepada 7000 pria dan wanita lajang dengan kisaran usia 29 hingga 30 tahun menunjukkan bahwa $40 \%$ dari mereka tidak tertarik untuk menjalin hubungan asmara. Alasan terbanyak yakni 46.2\% menyatakan bahwa menjalin hubugan asmara merupakan suatu hal yang merepotkan dan sebanyak $45.1 \%$ menunjukkan bahwa mereka ingin lebih fokus pada karir dan hobinya. Sedangkan, 
alasan lainnya menyatakan bahwa mereka tidak mengerti bagaimana cara untuk memulai suatu hubungan asmara dan menemukan pasangan. Selain karena faktor tersebut, ada faktor lain yang melatarbelakangi menjamurnya jasa biro jodoh di Jepang, salah satunya adalah rendahnya angka kelahiran di Jepang. Bahkan di tahun2014 Perdana Menteri Jepang, Shinzo Abe telah mengalokasikan dana sebesar tiga miliyar yen untuk mendukung program peningkatan angka kelahiran sebagai strategi untuk menaikan angka kelahiran yang menyusut. Populasi Jepang diperkirakan akan kehilangan sepertiga dari jumlah penduduknya dalam 50 tahun ke depan jika keadaan ini terus berlanjut.Dukungan pemerintah bagi kaum muda untuk segera menikah dan berumah tangga dianggap sebagai salah satu cara atau strategi dari pemerintah demi meningkatkan angka kelahiran. Untuk itu, pemerintah Jepang tak segan-segan untuk mengalokasikan banyak dana untuk proyek yang berkaitan dengan mendukung program menikah muda dan program lain yang bertujuan untuk meningkatkan populasi masyarakat Jepang .Maka dari itu, acara perjodohan yang diselenggarakan oleh biro jodoh lokal, di mana para wanita dan pria lajang akan diperkenalkan satu sama lain dalam suasana romantis, menjadi semakin umum di Jepang bahkan di daerahdaerah pedesaan, contohnya seperti daerah Kochi, sebuah prefektur sekitar 500 mil sebelah barat Tokyo. Pemerintah daerah Kochi akan menyiapkan sebuah jamuan makan malam di sebuah kafe, lengkap dengan musik live piano yang romantis, agar pasangan yang dijodohkan tersebut bisa terbawa suasana dan saling merasa cocok hingga akhirnya memutuskan untuk menikah. Angka resmi tahun lalu menunjukkan bahwa jumlah kelahiran turun menjadi 1,03 juta, terendah sejak data dimulai pada tahun 1899. Atas dasar itulah, di Jepang banyak ditemukan jasa biro jodoh atau sejenisnya. Hingga pada tahun 2015, jagat hiburan di Jepang dikejutkan dengan berita pernikahan Maki Horikita dan Koji Yamamoto. Mereka diketahui sebagai rekan sesama artis dan telah menjalin hubungan sebagai teman biasa. Dari pernikahan mereka, munculah konsep Kousai Zero Nichikon, jika diterjemahkan ke dalam bahasa Indonesia diartikan "menikah tanpa berkencan". Dalam konsep Kousai Zero Nichikon perjodohan dilakukan dengan bantuan perantara, sama halnya dengan omiai. Namun dalam kasus ini, yang dinikahi adalah orang yang sebelumnya sudah dikenalkan oleh teman dan pria atau wanita tersebut menjalin hubungan pertemanan terlebih dahulu, barulah jika merasa sudah ingin menikah dan saling merasa cocok, pernikahan bisa dilakukan.Menurut kumpulan cerita yang dihimpun oleh Matome Naver terkait fenomena tersebut, banyak masyarakat Jepang yang memilih untuk menikah dengan teman atau orang yang sudah mereka kenal, karena menurut mereka, hal itu akan menghemat waktu dan biaya yang akan dikeluarkan ketika berkencan.Pendapat tersebut didukung oleh Professor Masahiro Yamada, seorang sosiolog di Universitas Chuo di Tokyo, menunjukkan bahwa banyak kaum muda di Jepang merasa terbebani akan sebuah komitmen yang berhubungan dengan finansial ketika berkencan dan hal itu semakin lama bergeser dengan pemahaman bahwa akan lebih mudah jika menikah dengan orang yang sudah membuat nyaman. Hal itu membuktikan bahwa kaum muda di Jepang sangat mengindari kencan karena tidak ingin menambah beban finansial dalam hidup mereka.Peran pemerintah Shinzo Abe dalam meningkatkan angka kelahiran bisa dilihat pada usaha dalam menambah jumlah karyawan wanita. Namun strategi tersebut rupanya tak sejalan dengan realita. Masyarakat Jepang masih ada yang beranggapan bahwa tempat wanita setelah berumah tangga adalah di rumah. Menurut Machiko Osawa, seorang ekonom dan pengamat tenaga kerja di Japan Women's University, banyak dari 
masyarakat Jepang khususnya yang masih tradisional mempercayai bahwa jika mendukung wanita untuk berkarir hanya akan mengurangi angka kelahiran, dan berujung pada tingginya angka perceraian. Peran pemerintah dianggap telah maksimal hingga titik dimana pemerintah Jepang mengucurkan banyak dana untuk kegiatan perjodohan dan bahkan pemerintah turut berperan langsung menjadi mak comblang atau bisa diartkan sebagai perantara atau orang yang berjasa dalam menjodohkan. Bahkan hampir di tiap daerah di Jepang mempunyai situs perjodohan yang ditangani langsung oleh aparat pemerintahan. Salah satunya adalah daerah Fukui. Situs perjodohan di daerah bagian barat Jepang tersebut telah aktif sejak tahun 2010 dan menjadikannya sebagai pelopor biro jodoh yang didukung oleh pemerintah Jepang.

Prefektur Hiroshima telah berhasil meraih kesuksesan akan situs biro jodohnya. Hal tersebut dibuktikan dengan lima belas pasangan yang berhasil mencapai jenjang pernikahan. Gambar pasangan yang sukses ditempel pada brosur di Hiroshima sebagai pengingat agar pria atau wanita yang masih lajang bisa segara menikah. Seolah tak ingin kalah, bisnis swasta juga mulai bermunculan, dengan berbagai terobosan program yang menarik seperti sekolah kencan di prefektur Ibaraki di pantai timur, di mana seseorang bernama Kyoko Ishiduka menasihati para pria dan wanita lajang tentang bagaimana saling berkomunikasi. Namun sayangnya, dalam kurun waktu tiga tahun di Ishioka hanya menghasilkan dua pasangan suami istri. Maka pemerintah mencoba pilihan lain, termasuk uang saku perumahan bagi mereka yang menikah dan membebaskan pendidikan awal untuk keluarga dengan setidaknya tiga anak.

\section{SIMPULAN}

Krisis angka kelahiran di Jepang yang semakin mengkhawatirkan mendasari pemerintah untuk melakukan berbagai macam cara supaya dapat meningkatkan angka populasi di Jepang salah satunya dengan menggiatkan dan menyuarakan program yang berkaitan dengan pernikahan dan rumah tangga. Hal tersebut sudah dilakukan dari zaman dahulu, yakni dengan omiai atau perjodohan.Namun seiring berkembangnya zaman teknologi semakin berkembang pula pola pikir masyarakatnya.

Untuk mendapatkan jodoh bisa dilakukan dengan cara yang lebih mudah yakni ewat online atau bahkan menikah dengan teman atau orang yang sudah dikenal. Karena masyarakat Jepang yang cenderung berfokus pada karir, maka mereka tidak ingin jika harus membuang waktu dan uang mereka untuk berkencan. Untuk itu, mereka akan lebih memilih untuk menikah dengan seseorang yang sebelumnya sudah mereka kenal atau bisa disebut sebagai tren Kousai Zero Nichikon. Meskipun begitu, tren tersebut tampaknya tak bisa secara signifikan membantu program pemerintah untuk meningkatkan angka kelahiran.

Pemerintah Jepang menciptakan banyak strategi untuk terus meningkatkan angka kelahiran hingga ke pedesaan Jepang. Bahkan pemerintah tak segan untuk terjun langsung dengan membuat beberapa situs biro jodoh yang akan membantu pria dan wanita lajang untuk menemukan jodohnya sehingga menjadi pasangan yang akan menikah dan diharapkan untuk memiliki anak guna meningkatkan jumlah populasi penduduk Jepang.

\section{DAFTAR PUSTAKA}

Gulliver, Katrina. 2012. Modern Women in China and Japan : Gender,Feminism, and Global Modernity Between the wars .Jakarta :

I.B Tauris.Vol. 2. Japans's Birthrate Drops Below 1 Million: 2016 Demographic Statistics. http://www.nippon.com/en/features/h0 0160/. Diunduh 2 Desember 2017. 
Lebra, Takie Sugiyama. 1984. Japanese Women: Constraint and Fulfillment. Honolulu: University of Hawaii Press.

Masahiro, Yamada. Japan's Deepening Social Divides: Last Days for "Parasite Singles". http://www.nippon.com/en/indepth/a01002/. Diunduh 2 Desember 2017.

May, Jennifer. Matchmaking in Japan. https://www.japanvisitor.com/japanese -culture/match-making . Diunduh 2 Desember 2017

Nabilla , Fildzah. 2015. Strategi Pemerintah Jepang Dalam Upaya Meningkatkan Jumlah Kelahiran Pada Periode Pemerintahan Perdana Menteri Shinzo Abe. Yogyakarta: Universitas Gadjah Mada

Swann, W.B. Jr. Self Verification : Bringing Social Reality into Harmony with the Self. Hillsdale, NJ: Erlbaum.
Tokuhiro, Yoko. 2009. Marriage in Contemporary Japan. Routledge.

Unsriana, Linda. 2014. Perubahan Cara Pandang wanita jepang terhadap Perkawinan dan kaitannya dengan shoushika. Jurnal Humaniora Binus University, Jakarta.

Widiandari, Arsi. 2016. Fenomena Shoushika di Jepang: Perubahan Konsep Anak. Semarang: Izumi (http://ejournal.undip.ac.id/index.php/i zumi). Vol.5:32-33

Yoshikata, Ishikawa. 2010. Matchmaking Agencies for International Role of Marriage in Contemporary Japan. Department of Geography, Graduate School of Letters, Kyoto University. Available from: https://www.jstage.jst.go.jp/article/geo grevjapanb/83/1/83_1_1/_pdf/-char/en 